\title{
MARIANA CAVALLEIRO DE MACEDO: TRAJETÓRIA DE UMA NORMALISTA MODELO
}

MARICILDE OLIVEIRA COELHO*

Resumo: Este artigo tem por objetivo relacionar fatos da vida profissional e pessoal da professora normalista Mariana Cavalleiro de Macedo Vianna com o momento histórico vivenciado pela educação brasileira após a proclamação da República. A referida professora atuou no magistério, nas primeiras décadas da implantação do regime republicano brasileiro quando se evidenciou a institucionalização da escola primária como modelo de organização de ensino racionalizado, padronizado e universalizado. A incumbência atribuída à escola no projeto político e social pensado pelos republicanos era o de formar o cidadão ordeiro, preocupado e empenhado com o progresso social e material do país. Diversas medidas foram instituídas pelo governo republicano brasileiro para renovar o papel conferido à instrução popular. Entre estas medidas, surgem: os grupos escolares, mudança nos programas curriculares de ensino, adoção de modernos métodos pedagógicos, uso de diversos materiais didáticos e livros escolares, publicações de revistas especializadas em educação e uma política de formação para o professor primário, com reformas no curso normal. Além do trabalho no magistério, Mariana Cavalleiro de Macedo Vianna contribuiu na sessão "Contos Infantis" do periódico pedagógico $A$ Escola, e, ao escrever historietas, aderiu a princípios e valores do projeto pensado para as crianças e os jovens do início do século XX: plasmar modelos de virtudes morais e patriotismo. A visibilidade ao trajeto pessoal e profissional de Mariana Cavalleiro de Macedo Vianna, registrada nos documentos pesquisados, revela as ideias e ações de uma mulher que atuou de forma ampla, quer seja como educadora ou como escritora, no processo de identificação da nova geração com o republicanismo.

Palavras-chave: Intelectual, Gênero, Profissão docente.

\section{Mariana Cavalleiro de Macedo: the trajectory of a normalist model}

Abstract: This article aims to relate facts of the professional and personal life of the teacher Mariana Cavalleiro de Macedo Vianna, a normalist who adhered to the principles and values of the project designed for children and young people of the early twentieth century: to make models of moral virtues and patriotism. Mariana Cavalleiro de Macedo Vianna acted as teacher in the historical moment post proclamation of the Republic, when the institutionalization of primary school was evidenced as a model of a rationalized, standardized and universalized teaching organization. Several measures were instituted by the Brazilian republican government to renew the role of popular instruction, among them, the implementation of school groups, changes in curricula of teaching, adoption of modern pedagogical methods, use of various teaching materials and textbooks in the classrooms, publications of specialized journals in education and a training policy for the primary teacher, with reforms in the normal course. In addition to her teaching work, Mariana Cavalleiro de Macedo Vianna also contributed to the "Contos Infantis" section of the pedagogical journal A Escola. The visibility of Mariana

\footnotetext{
* Doutora em Educação pela USP. Realizou estágio de pós-doutorado na Universidade Federal de Minas Gerais (UFMG).
} 
Cavalleiro de Macedo Vianna's personal and professional trajectory, recorded in the documents researched, reveals the ideas and actions of a woman who acted broadly, whether as an educator or as a writer, in the process of identifying the new generation with the republicanism.

Keywords: Thinker, Genre, Teaching profession.

Este artigo apresenta fatos da vida profissional e pessoal de Mariana Cavalleiro de Macedo Vianna, que desempenhou as funções de professora normalista e escritora de contos infantis em Belém do Pará do final do século XIX, produzindo e refletindo sobre a instrução e o modo de instruir a infância brasileira. Quando de seu precoce falecimento, aos 24 anos, foi considerada um modelo a ser seguido por outros professores. Essa professora viveu em um momento histórico, o início da república brasileira, em que a educação e a instrução foram vistas, pelo ideário republicano, como uma das vias de civilizar e modernizar a nação. Esses estudos têm o objetivo de investigar um fragmento da realidade social-histórica a partir de uma determinada pessoa, situada em grupo social, num determinado tempo histórico, e de compreender, por meio indiciário da vida pessoal e profissional de Mariana Cavalleiro de Macedo Vianna, as configurações das relações sociais, os mecanismos e os processos do contexto social no qual elas se inscreveram.

Mariana Cavalleiro de Macedo nasceu em Belém no dia quatro de novembro de 1876. Em 1894, com dezoito anos de idade, concluiu o curso de normalista na primeira turma de alunos formados após a reorganização da Escola Normal. Na república, a Escola Normal passou a ser representada nos discursos oficiais como o ninho do saber e da propagação da luz, ou seja, ao contrário do ensino normal no Império, descontínuo e com um histórico de projetos irrealizados, a República consolidou a Escola Normal como espaço de formação de professores capazes de garantir uma educação "salvadora da sociedade" (Nagle, 2001). A titulação dos professores pela Escola Normal passou a ser condição fundamental e imprescindível nos melhoramentos previstos para a instrução pública. Num trecho do discurso do governador Lauro Sodré (1852-1944) sobre a colação de grau da turma de normalistas que Mariana Cavalleiro de Macedo fazia parte, em janeiro de 1894, se observa como era considerada esta instituição:

[...] condição essencial e indispensável para o levantamento do nível da instrução pública. D’esse importante estabelecimento de ensino, 
base e ponto inicial de toda organização da nossa Pátria, como a desejamos e queremos, esclarecidos todos os espíritos, educados todos os cidadãos para o exercício das funções que lhes cabem sob o regime democrático, saíram já os primeiros resultados, tendo a primeira turma dos novos professores normais completado o curso (Pará, 1894, p.24.).

O governador, orgulhoso da formação da primeira turma de professores no novo modelo político do país, não poupou elogios aos responsáveis pela educação nesse regime democrático: os normalistas, esclarecedores de todos os espíritos. A primeira turma de normalistas da nova Escola Normal do Estado diplomou-se com as seguintes alunas: Mariana Hesketh Cavallero de Macedo, Sirena de Castro Valente, Maria Guajarina de Lemos, Ernestina Braga, Maria StellinaValmont, Maria José Baena, Vicentina Silva e com os seguintes alunos: José Procópio Correa Pinto e Fábio D’Andrade e Silva (Jornal A República, p.2).

Pela relação de nomes dos alunos da turma que colou grau pela Escola Normal do Pará em 1894, observa-se um número maior de mulheres do que de homens. No total de nove formandos, sete eram mulheres e apenas dois homens. Ensinar as primeiras letras, a princípio um ofício marcadamente masculino, passa a ser a partir da segunda metade do século XIX, no Brasil e em outros países do mundo, expressivamente feminino. Para se ter uma ideia, em 1855, dos 51 professores primários da Província do Pará, apenas sete eram mulheres (Pará, 1855). Trinta anos depois, já em 1885, a matrícula de homens na Escola Normal do Estado era consideravelmente inferior ao número de mulheres, pois estavam regularmente matriculados cem alunas e dezesseis alunos e nesse mesmo ano, completaram o curso normal, sete alunos e vinte e três alunas (Pará, 1885).

Na última década do século XIX estava claro o afastamento dos homens da lide do magistério primário. Em 1894, o diretor da instrução pública do Pará, Alexandre Vaz Tavares (1858-1994), justificou essa situação devido a dois motivos: o primeiro era o fato do curso normal ser o mais elevado grau de ensino para as mulheres, enquanto que aos homens era permitido seguir estudos que levassem para outras profissões, como por exemplo, Medicina, Engenharia ou Direito e o segundo motivo era a irrisória retribuição pecuniária ao trabalho do professor primário (Pará, 1896). Preocupado com os encargos que cabiam ao homem, Alexandre Tavares levantou a possibilidade 
de aplicar a "medida acertadíssima" de diferenciar os salários dos professores do sexo masculino:

Tenho notado nas leituras que hei feito do orçamento escolar de vários países, que há sempre uma diferença entre os vencimentos do professor e das professoras, nos cursos secundários, como acontece em França. E acho n'isto sua razão de ser, que desfaz toda e qualquer ideia de justiça que se venha ter a propósito. É que a professora sendo solteira não tem filhos a criar, quando muito terá irmãs ou mesmo mãe que a auxiliem na sustentação da família; sendo casada, possui o marido que deve zelar mais do que ela pela manutenção doméstica. O que não acontece com o professor que, solteiro ou casado (e é sempre conveniente que seja casado) tem quase sempre a seu encargo o provimento das necessidades de muitas pessoas (Pará, 1896, p. 249).

Alexandre Tavares considerava o exercício da docência pela mulher uma profissão auxiliar e de complemento ao orçamento familiar, enquanto que ao homem caberia assumir os encargos de manutenção da família. Assim, era "acertadíssima" a medida proposta do aumento de salários dos professores do sexo masculino, até porque a medida estava respaldada no exemplo de como a França, um país considerado civilizado e desenvolvido, aplicava seu orçamento na educação. O processo de modernidade vivenciado em Belém no final do século XIX, expresso pelo desenvolvimento da vida cultural urbana, influenciado pela ideologia de progresso político e moral das civilizações burguesas (Sarges, 2000), também se estendeu à pedagogia, sendo a prática pedagógica estrangeira, em especial a francesa, modelo para o Brasil.

A medida salarial proposta por Alexandre Vaz Tavares, entretanto, não apresentou resultados satisfatórios e não atraiu os homens para o magistério das séries iniciais. Três décadas após o relatório de Alexandre Vaz Tavares, estavam matriculados na Escola Normal do Estado em 1926, 263 alunos, sendo apenas seis do sexo masculino (Pará, 1926). Essa ocorrência se assemelhava em vários países do mundo, e na década de 1930, é quase absoluta a participação das mulheres no magistério das séries elementares. Na Inglaterra, em 1930, a cada 100 professores, correspondiam 366 professoras. No mesmo ano, nos Estados Unidos, elas eram 89,5\% do professorado e em Portugal, em 1926, as mulheres representavam 66\% do magistério.

Representante do crescimento feminino no magistério, a normalista Mariana 
Cavalleiro de Macedo teve seus créditos de excelente estudante reconhecido pela Diretoria de Instrução Pública e assim, recebeu a nomeação para reger interinamente a Escola Modelo elementar, anexa à Escola Normal como prêmio. No ano seguinte, ao submeter-se a concurso para professor efetivo de escolas da capital, foi aprovada e assumiu, no dia primeiro de maio de 1895, a 11‥ Escola do 4ㅇ. Distrito da Capital, situada na casa número 93 da Estrada de São Jerônimo (atual Avenida Governador José Malcher).

Seguindo as regras da moral e dos bons costumes, Mariana Cavalleiro de Macedo casou no dia nove de setembro de 1897 com o professor Arthur Octavio Nobre Vianna. No ano seguinte, seu marido foi comissionado para recolher informações e documentos que elucidassem a questão de limites entre os Estados do Pará e do Amazonas e na condição de esposa, Mariana de Macedo acompanhou o marido na expedição, posteriormente registrada no livro de Vianna intitulado Estudos sobre o Pará: limites do Estado (1899-1901). Observa-se que na organização familiar do casal Vianna, há uma demarcação dos papéis sociais tradicionalmente assumidos pelos cônjuges, cabendo à mulher seguir o marido em sua empreitada, o que fez Mariana de Macedo Vianna abandonar, por um período, seus afazeres de professora.

Ao retornar à capital paraense, em 1899, passou a reger a escola complementar do sexo feminino do 4ㅇ. Distrito de Belém. Dentre as alunas da professora Mariana Cavalleiro de Macedo Vianna no ensino primário, várias se tornaram professoras normalistas de grupos escolares do Pará, entre elas: Lucila Vianna, Antonina Nunes, Julia Hollanda, Eulina Cardoso, Paula Barbosa, Maria Netta, Edelvira Cardoso e Graziella Moura. Também foi aluno de Mariana Cavalleiro de Macedo Vianna o menino Gaspar Vianna (1886-1914), futuro médico bacteriologista, que viria a trabalhar com Oswaldo Cruz no Instituto Manguinhos, no Rio de Janeiro (Valmont, 1901).

O período em que Mariana Cavalleiro de Macedo Vianna atuou no magistério foi a primeira década da implantação do regime republicano brasileiro, que se evidenciou pela institucionalização da escola primária como modelo de organização de ensino racionalizado, padronizado e universalizado. A incumbência atribuída à escola no projeto político e social pensado pelos republicanos era o de formar o cidadão ordeiro, preocupado e empenhado com o progresso social e material do país. Para exercer essa missão, os professores primários foram chamados a "semear o pão do espírito", e di- 
versas medidas foram instituídas pelo governo republicano brasileiro para renovar o papel conferido à instrução popular. Entre estas medidas, a implantação dos grupos escolares, as mudanças nos programas curriculares de ensino, a adoção de modernos métodos pedagógicos, o uso de diversos materiais didáticos e livros escolares, publicações de revistas especializadas em educação e uma política de formação do professor primário, com reformas no curso normal.

A "nova Escola Normal”, aonde Mariana Cavalleiro de Macedo Vianna realizou seus estudos, nasceu com o objetivo de ser o espaço privilegiado da formação do professor primário, considerado o multiplicador das luzes, o impulsionador da História em direção ao progresso e a liberdade. Para os educadores republicanos, naquele momento, a escola deveria substituir o saber fragmentado por uma síntese científica e o ensino da Escola Normal foi orientado por uma ordenação científica do conhecimento, onde o mérito das ciências matemáticas, astronômicas, físicas, químicas e biológicas era considerado superior. Essas disciplinas foram consideradas básicas para o exercício da pedagogia, e, portanto, com carga horária expressiva no programa, enquanto o ensino da própria pedagogia aparece com uma carga horária menor.

A educação na Escola Normal para os futuros professores incluiu o ensino da esgrima e da ginástica para os meninos, de exercícios físicos e de prendas domésticas para meninas, e a instrução musical para todos, com o fim de alcançar a educação integral. Nos anos iniciais do governo republicano paraense também foram realizados investimentos na reforma material da Escola Normal, com melhorias do espaço físico da Escola, com a construção da biblioteca, do laboratório de física e química e do museu pedagógico (Pará, 1896). Essas ações convergiram no sentido de acentuar a necessidade de integrar diferentes dimensões do trabalho docente e obter melhores resultados quanto à qualidade do ensino.

Oriunda de um grupo social privilegiado, Mariana Cavalleiro de Macedo Vianna recebeu instrução e educação acrescida de elementos que permitiram com que circulasse na sociedade e em especial, no magistério, de maneira a imprimir marcas na sua forma de trabalhar e ver a importância da instrução. Na apresentação feita por Mariana Cavalleiro de Macedo à Diretoria de Instrução Pública sobre o trabalho docente que desenvolveu no ano letivo de 1896, quando atuou como professora da 11ä. Escola Feminina da Capital, a mesma faz referências a notícias animadoras da instrução e da 
educação nos países considerados avançados. Entre os países invocados por Mariana Cavalleiro de Macedo Vianna aparecem as três potências europeias (França, Alemanha e Inglaterra) e os Estados Unidos, uma potência ascendente à escala mundial, além da Suíça e Bélgica, polos de produção e divulgação de discursos científicos e técnicos sobre a nova pedagogia.

As informações acerca da situação da escola e da pedagogia nos países estrangeiros revelam que Mariana Cavalleiro de Macedo Vianna via esses países como modelos nas questões pedagógicas. Segundo a professora, no Brasil a instrução sofria de dois males: a indiferença do meio e a organização defeituosa da escola. Para exemplificar a ausência de interesse da família pela instrução dos filhos, a professora cita o caso de uma aluna que, mesmo durante o ano letivo, passa meses veraneando com a família. Ao mesmo tempo, Mariana Cavalleiro de Macedo Vianna louva os avanços alcançados pela instrução no curto prazo da implantação do regime republicano, reforçando o que Alessandra Schueler e Margareth Magaldi (2009) chamam de "representações cristalizadas da educação popular", ou seja, imagens da educação popular que foram construídas a partir do advento da República brasileira, quando há uma desconsideração do que se alcançou nesse setor durante o período monárquico. Um trecho do relato de Mariana Macedo ilustra esse pensamento:

Ninguém poderá negar, a menos que se deixe arrastar pela cegueira
das paixões, o progresso alcançado pela instrução pública no septue-
nio republicano.
Para convicção desta verdade é indispensável não tomar como ponto
de reparo o estado atual do ensino público, que ainda é, evidente-
mente, atrasado. É preciso considerar que a sete anos atrás, quando
proclamou-se a República, a instrução primária achava-se no mais
deplorável estado, era "tristissimamente precária", na frase do Sr. Jo-
sé Veríssimo, é preciso considerar a nudez absoluta em que vivia a
escola paraense, e poderemos então aquilatar o grau de desenvolvi-
mento desde importante ramo dos negócios públicos (Macedo, 1901)

No mesmo relatório, porém, a professora reconheceu as dificuldades da "árdua missão para o progresso da escola": elevado número de matrículas, frequência irregular dos alunos, ausência do interesse e dedicação da família, dúvidas na aplicação de uma metodologia eficaz para o ensino da leitura e da escrita. Somado a esses fatores, que "retardam a marcha da instrução", faltava ao Governo do Estado construir prédios 
apropriados e destinados exclusivamente ao ensino primário, pois, nas palavras de Mariana "enquanto à escola paraense faltar luz e comodidade, ventilação, recreios, preceitos higiênicos, o progredimento será demorado, às reformas úteis faltará base, a organização antiga prevalecerá indefinidamente" (Macedo,1901).

Nota-se que a professora não se mostrou alheia e indiferente aos obstáculos enfrentados pela precariedade da instrução pública no Estado do Pará, e sim, comprometida com o contexto social do qual fazia parte. Mariana Cavalleiro de Macedo considerava que uma das maiores dificuldades para realizar o trabalho docente estava na ausência de um espaço apropriado para o ensino primário, que àquela época se realizava em igrejas, na casa do professor ou em salas alugadas. No Brasil, discussões sobre a necessidade da construção de prédios para a escola primária remontam desde meados do século XIX, e na Província do Pará, são encontradas reivindicações acerca das edificações escolares nos relatórios dos diretores da instrução pública, Joaquim Pedro Corrêa de Freitas (1881), Domingos Nina Ribeiro (1889) e José Veríssimo (1890). Somente em 1901, após a proclamação da República, o Governo do Estado do Pará inaugurou o primeiro Grupo Escolar da capital paraense, um novo conceito arquitetônico de espaço destinado ao ensino, com seis salas de aula, biblioteca, pátio para recreio, laboratório e auditório. Mesmo assim, as precárias escolas isoladas dividiram com os Grupos Escolares o espaço educativo no decorrer do século XX.

Além do trabalho no magistério primário, Mariana Cavalleiro de Macedo Vianna colaborou com a sessão "Contos Infantis" da revista A Escola- Revista oficial do ensino, periódico pedagógico de responsabilidade da Diretoria Geral de Instrução Pública do Governo do Estado do Pará, escrevendo historietas para a infância. Para Denice Barbara Catani e Maria Helena Camara Bastos ( 2002) o estudo de revistas especializadas em educação constitue uma instancia privilegiada para apreensão do campo eduacional. Na revista $A$ Escola circularam informações sobre o trabalho pedagógico que pemitiram, em conjunto com outros documentos, analisar a configuração do campo pedagógico no período inicial da república, quando surgem novas exigências na constituição da identidade profissional do professor.

A produção literária de Mariana Cavalleiro de Macedo Vianna, encontrada nas páginas da revista $A$ Escola auxiliaram na constituição do pensamento, da prática e da ação pedagógica ao vincular modelos de docência. Castro Pinto, inspetor de ensino e 
editor da revista A Escola, apresentou o conto infantil Coração de ouro (1900), escrito por Mariana Cavalleiro de Macedo para o primeiro número da revista, em maio de 1900, como a melhor maneira de se ensinar História "para o estudante em tão verdes anos", pois o conto, ao falar à imaginação, proporcionava maior proveito e estímulo do ensino entre as crianças (Pinto,1900). A lição de moral "disfarçada na poesia cativante de uma ligeira narração fantasiosa, cujo enredo traduz um conselho e um exemplo" e a História Pátria "dita do modo mais acessível e agradável", presentes na produção literária de Mariana Cavalleiro de Macedo Vianna, revelam quais as recomendações reservadas para a infância brasileira naquele período histórico. Seus contos desvendam a constituição do ideário cívico e moral da escola primária em narrativas que entrelaçam o ensino da História com o ensino de lições morais e patrióticas, ampliando a função social da escola e da instrução.

Em seus contos, Mariana Cavalleiro de Macedo Vianna trata dos costumes e do cotidiano de crianças, ricas e pobres, especialmente de meninos, vivendo em situações conflituosas. Seus contos expõem um mundo em que existem desigualdades e injustiças, mas também, a partir de uma consciência humanitária, sobrepõem-se a solidariedade, a honestidade e a justiça, fatores preponderantes na construção de uma vida segura. As várias transformações pelas quais passou a sociedade brasileira, a partir da segunda metade do século XIX, reiteraram a necessidade da disciplina, da instrução, do trabalho e da benevolência como armas sociais no controle aos conflitos e tensões de um estado altamente estratificado. As historietas de Mariana Cavalleiro de Macedo Vianna contribuíram na missão civilizadora e definiram comportamentos esperados da criança diante de uma sociedade em acelerada transformação.

O conto Coração de ouro (1900) retrata a amizade de dois meninos: Carlos, um menino criança abastado, e Gigi, um garoto pobre trabalhador, que quase morreu quando "aquela maldita roda" da fábrica machucou seu pé. Na visita que faz a Gigi, Carlos percebe no amigo a preocupação com as despesas do tratamento e da casa, pois ficara sem o salário. Carlos resolve então, trabalhar na fábrica para ajudar financeiramente a família de Gigi, ao invés de ir para a escola. Para isso, mente para a mãe. Ao fim de uma semana, Carlos recebe o dinheiro de seu trabalho e o entrega para Gigi. A mãe de Gigi vem até a casa de Carlos para agradecer. É quando a família de Carlos descobre a mentira, perdoada por ter um fim humanitário e cristão. 
No decorrer das primeiras décadas republicanas, o trabalho infantil, pano de fundo do conto Coração de ouro, permaneceu como elemento significante na contenção dos custos de produção da indústria brasileira, definindo ainda mais a espoliação das classes oprimidas, que dificilmente poderiam não permitir o trabalho de seus fiIhos. Mariana Cavalleiro de Macedo Vianna denuncia, no conto, as péssimas condições de trabalho e a situação de crianças operárias na indústria brasileiras daquela época, quando ocorria um elevado índice de acidentes sofridos pelos trabalhadores (Moura, 2008).

No conto Abnegação infantil (1900) há a preocupação com o ensino da História e o ensinamento de valores morais. Na véspera da cabanagem, segundo a autora um "período de anarquia, desrespeito às leis, às autoridades e aos poderes legais", o capitão João Coelho de Miranda Leão, o "Quebra - corrente", tem como certa a prisão do cônego Batista Campos, abrigado em uma casa na rua dos Mártires (atual Rua 28 de Setembro). Cercado pelos soldados de "Quebra - corrente", Batista Campos acredita que poderia salvar-se enviando uma carta ao comandante da corveta "Campista", atracada nas Docas. Uma criança de 13 anos, José Coelho da Motta, se propõe a levar a carta e sai pelos fundos da casa. Revistado pelas tropas inimigas, os soldados não descobrem a carta escondida na palmilha do sapato e assim, o menino consegue entregála ao destinatário. Mas ao retornar para a casa, o cônego Batista Campos já havia sido detido e arrastado às ruas por seus adversários. Decepcionado pelo ocorrido, o menino ouve a voz de sua consciência a dizer-Ihe que cumprira o seu dever e tudo quanto humanamente era possível fazer, ele o fizera.

O conto O pequeno herói (1900) descreve um episódio da guerra do Paraguai, quando o general brasileiro Manoel Luiz Ozório luta contra o ditador paraguaio Francisco Solano Lopes. Eduardo, filho do general brasileiro, de 15 anos incompletos, rogou ao pai para ir para a guerra, marchar e defender sua terra. Diante disso, a mãe permitiu ao jovem participar da batalha. No dia 10 de junho de 1865, a esquadra brasileira comandada pelo almirante Barroso fundeara perto de Riachuelo. Temendo a morte do filho, o general Manoel Luiz Ozório, ordena a Eduardo que abandone a luta. O jovem, porém, insiste em ficar: "A morte não deve ser um obstáculo senão um prêmio para os que defendem seu país". Orgulhoso da coragem do filho, o pai deixa que ele cumpra seu dever. Na troca tiros de canhões entre a esquadra brasileira e a esquadra para- 
guaia, Eduardo recebe um golpe de baioneta do último vapor inimigo que se lançou sobre a corveta e morre.

Eduardo, o pequeno herói do conto de Mariana Cavallero de Macedo Vianna não faz parte da estatística de recrutamento forçado de crianças, principalmente as oriundas de famílias economicamente desfavorecidas, durante o período da Guerra do Paraguai, quando os burocratas imperiais enviaram inúmeras crianças sem treinamento nenhum, aos campos de batalha. Eduardo é um herói, filho de um militar, e acredita que deve amor, lealdade e fidelidade à pátria. Mesmo considerando o caráter heroico de Eduardo, um personagem da literatura, não se pode esquecer que o estado imperial facultou o acesso arriscado de crianças a situações de conflito armado (Venâncio,1999).

Considera-se, na leitura dos três contos escritos por Mariana Cavallero de Macedo Vianna, que o pano de fundo é o patriotismo e as boas ações, valores necessários às condições do tempo e do espaço em que foram produzidos. Mas não se pode esquecer que a autora denunciou as difíceis condições sociais em que vivia grande parte das crianças brasileiras, como o personagem Gigi do conto Coração de ouro e a presença de crianças exposta ao perigo de balas de metralhadoras e canhões na guerra no conto $O$ pequeno herói. As aventuras e os sofrimentos presentes nos contos escritos por Mariana Cavallero de Macedo Vianna levavam o público a se emocionar, mas também prescreviam comportamentos e condutas, imprimindo uma experiência formativa em que o público se identificava e se influenciava pelas virtudes e valores, como a solidariedade e a honestidade, dos personagens.

O súbito falecimento de Mariana Cavalleiro de Macedo Vianna no dia seis de novembro de 1900, vitimada no parto de seu primeiro filho, ocasionou comoção e luto na classe do professorado paraense. Em outubro de 1901, quase um ano após seu falecimento, a Diretoria Geral da Instrução Pública lançou um número especial da Revista A Escola com saudações e homenagens diversas à falecida mestra. As homenagens à Mariana de Macedo Vianna foram assinadas por Raymundo Bertoldo Nunes (diretor do 2‥ Grupo Escolar da Capital), professores Sebastião José Salgado Guimarães, Maria Pacheco de Guimarães, Antonio de Figueiredo Souza, Jeronyma de Carvalho Santos, Vicencia Faria da Silva, Maxima Alves Raiol, Gemina Pinto, Lucinda Christianna Maia, Graziela Moura, Mirandolina de Faria Damasceno, Belmira de Jesus, Maria de Belém 
Ferreira, Gregória Leão de Mattos, Raymunda Theresa de Mello, F. de Souza, R. Vianna, Maria Minervina Paes de Andrade, Catharina de Moraes Bittencourt e Virgilio Cardoso de Oliveira (Diretor Geral da Instrução Pública).

Este número especial da revista $A$ Escola trouxe uma série de referências acerca da vida pessoal e da vida profissional de Mariana Cavalleiro de Macedo Vianna, exaltando suas qualidades morais e sociais, suas virtudes e capacidades. Em 1903, no segundo aniversário da morte de Mariana Cavalleiro de Macedo Vianna, também aparece um artigo sobre a vida profissional da normalista assinado pelo professor Vilhena Alves. A repentina morte de Mariana Cavalleiro de Macedo Vianna também interrompeu o intento da mesma em transformar os contos avulsos, publicados mensalmente na revista, em um livro de leitura "com base na moral e instrução cívica" (Valmont, 1901).

O empenho da Diretoria Geral da Instrução Pública em divulgar um número especial da revista A Escola com a história de vida de Mariana Cavalleiro de Macedo Vianna lembra o que Martin Lawn (2000) chama de construção da identidade do professor. No Brasil, a escola primária, no período inicial da República, contribuiu para a circulação de um determinado modelo de ensino, ajustado à ideia de ordem e de progresso. Assim, a identidade do professor foi construída pelo Estado por meio dos programas de formação, regulamentos, serviços, encontros políticos e até discursos públicos. A vida pessoal e profissional de Mariana Cavalleiro de Macedo Vianna, exposta nas páginas da revista $A$ Escola, serviu para o Estado exibi-la como modelo para o professorado, que, ao se identificar com ele, assumiria o papel de divulgador de valores, discursos e projetos políticos para a escola e a instrução daquele momento histórico.

A história de vida de Mariana Cavalleiro de Macedo Vianna apresenta uma trajetória pessoal comum a várias mulheres e professoras de sua época, porém, percebese nesta educadora, o exercício de uma multiplicidade de atividades na sociedade em que estava inserida. Além do trabalho no magistério, contribuiu na sessão "Contos Infantis" do periódico A Escola, e com isso aderiu a princípios e valores do projeto pensado para as crianças e os jovens do início do século XX: plasmar modelos de virtudes morais e patriotismo. A visibilidade ao trajeto pessoal e profissional de Mariana Cavalleiro de Macedo Vianna, registrada na pesquisa, revela as ideias e ações de uma muIher que atuou de forma ampla, quer seja como educadora ou como escritora, no pro- 
cesso de identificação da nova geração com o republicanismo.

\section{Referências}

AMANAJÁS, H. 1898. Noções de Educação Cívica. 2ạ. ed. Belém, Tipografia da Imprensa Oficial.

BERTAUX, D. 2010 Narrativas de vida: a pesquisa e seus métodos. Natal-RN: EDUFRN; São Paulo: Paulus.

CARINO, J. 1999. A biografia e sua instrumentalidade educativa. Revista Educação e Sociedade, 67 (20): 153-181.

CATANI, D. B. \& BASTOS, M. H. C. 2002. Educação em revista - A imprensa pedagógica e a História da Educação. São Paulo: Escrituras Editora.

LAWN, M. 2000. Os professores e a fabricação de identidades. In: A. NÓVOA \& SCHRIEWER, J. (eds.). A difusão mundial da escola. Lisboa, Educa.

MACEDO, M. C. de. 1901. Excertos dos relatórios apresentados pela professora Marianna Cavalleiro de Macedo à Diretoria de Instrução Pública. Revista A Escola - Revista Oficial do Ensino, II (19): 20-26.

MOISÉS, M. 1987. A criação literária. 4ạ. edição, São Paulo, Cultrix.

MOURA, E. B. B de. 2008. Crianças operárias na recém-industrializada São Paulo. In: PRIORE, M. D. (org.). História das Crianças no Brasil. São Paulo, Contexto, 6ạ. edição, p. 259-288.

NAGLE, J. 2001. Educação e sociedade na Primeira República. Rio de Janeiro, D.P. \& A Editora.

NÓVOA, A. 1995. 2a e edição. Vidas de professores. Porto, Porto Editora.

PARÁ, Província. 1855. Mapa das cadeiras de instrução primária por Joaquim José de Assis, secretário de governo da Província do Pará. In: Fala dirigida a Assembleia Legislativa Provincial pelo exmo. Senador conselheiro Sebastião do Rego Barros, digno presidente desta província no dia 26 de outubro de 1855 por ocasião de abertura da segunda sessão ordinária da nona legislatura da mesma assembleia. Província do Pará: Tipografia Santos e Filhos.

1885. Fala com que o exmo. Sr. conselheiro Dr. João Silveira de Souza, presidente da Província do Pará, abriu a segunda sessão da 24ạ. legislatura da Assembléia Provincial em dezoito de abril de 1885. Pará: Tipografia da Gazeta de Notícias.

PARÁ, Estado. 1890. Relatório apresentado pelo Sr. José Veríssimo, Diretor Geral da Instrução Pública, ao Sr. Governador do Estado do Pará Dr. Justo Leite Chermont em 1890. Belém, Pará: Tipografia de Tavares Cardoso.

. 1896. Relatório das repartições estaduais apresentado ao Sr. Governador

Dr. Lauro Sodré em 1894. Belém: Typographia do Diário Official.

PINTO, J. C. 1900. Apresentação. Revista A Escola - Revista Oficial do Ensino. I (1): 3-6.

VALMONT, M. S. 1901. Marianna Macedo de Vianna. Revista A Escola-Revista Oficial do Ensino, II (19): 3-8.

VENÂNCIO, R. 1999. Os aprendizes da guerra. In: PRIORE, M. D. (org.). História das Crianças no Brasil. São Paulo, Contexto, 6a. edição, p. 192-209.

VIANNA, M. C. de. 1901. Excertos dos relatórios apresentados pela professora Marianna Cavalleiro de Macedo à Diretoria de Instrução Pública. Revista A Escola - Revista Oficial do Ensino, II (19): 20-26.

. 1900. Coração de ouro. Revista A Escola - Revista Oficial do Ensino. I (1): 3- 
6. 1900. Abnegação infantil. Revista A Escola - Revista Oficial do Ensino. I (2): $39-43$.

O pequeno herói. Revista A Escola - Revista Oficial do Ensino. I (3): 278-282. SARGES, M. N. 2000. Belém: Riquezas produzindo a belle-époque (1870-1912). Belém, Paka-tatu.

SCHUELER, A.; MAGALDI, A. M. 2009. Educação escolar na Primeira República: memória, história e perspectivas de pesquisa. Disponível em www.scielo.br/scielo.php. Acesso em 14/06/2010.

Artigo recebido em setembro de 2018 e aceito em novembro de 2018. 